\title{
Fabrication of compact and stable perovskite films with optimized precursor composition in the fast-growing procedure
}

\author{
Tanghao $\mathrm{Liu}^{1 \dagger}$, Yuanyuan $\mathrm{Zhou}^{2 \dagger}$, Qin $\mathrm{Hu}^{1,3}$, Ke Chen ${ }^{1}$, Yifei Zhang ${ }^{1}$, Wenqiang Yang ${ }^{1}$, Jiang Wu ${ }^{1}$, \\ Fengjun $\mathrm{Ye}^{1}$, Deying Luo ${ }^{1}$, Kai Zhu ${ }^{4}$, Nitin P. Padture ${ }^{2}$, Feng Liu ${ }^{3}$, Thomas Russell ${ }^{3}$, Rui Zhu ${ }^{1,5,6^{*}}$ \\ and Qihuang Gong ${ }^{1,5,6}$
}

\begin{abstract}
The fast-growing procedure (FGP) provides a simple, high-yield and lead $(\mathrm{Pb})$-release free method to prepare perovskite films. In the FGP, the ultra-dilute perovskite precursor solution is drop-cast onto a hot $\left(\sim 240^{\circ} \mathrm{C}\right)$ substrate, where a perovskite film grows immediately accompanied by the rapid evaporation of the host solvent. In this process, all the raw materials in the precursor solution are deposited into the final perovskite film. The potential pollution caused by $\mathrm{Pb}$ can be significantly reduced. Properties of the FGP-processed perovskite films can be modulated by the precursor composition. While $\mathrm{CH}_{3} \mathrm{NH}_{3} \mathrm{Cl}$ (MACl) affects the crystallization process and leads to full surface coverage, $\mathrm{CH}\left(\mathrm{NH}_{2}\right)_{2} \mathrm{I}$ (FAI) enhances the thermal stability of the film. Based on the optimized precursor composition of $\mathrm{PbI}_{2} \cdot(1-x) \mathrm{FAI} \cdot x \mathrm{MACl}, x=0.75$, FGP-processed planar heterojunction perovskite solar cells exhibit power conversion efficiencies (PCEs) exceeding 15\% with suppressed hysteresis and excellent reproducibility.
\end{abstract}

Keywords: fast-growing procedure, lead-release free, precursor composition, surface coverage, thermal stability

\section{INTRODUCTION}

Since the first use of hybrid organic-inorganic perovskites (HOIPs) as light absorbers in solar cells in 2009 [1], tremendous efforts have been devoted to improving the power conversion efficiencies (PCEs) of perovskite solar cells (PSCs) [2-12]. Now, the record PCE of PSCs has exceeded 20\%, which represents unprecedented promise in the commercialization $[13,14]$. The rapid rise of PSCs is owing to the outstanding optoelectronic properties of these HOIPs, including tunable bandgaps, high absorption coefficients and long carrier diffusion lengths [15-17].

However, to-date, most high-PCE PSCs contain soluble lead $(\mathrm{Pb})$, which has drawn significant environmental concern. $\mathrm{Pb}$ can be released from the fabrication and the deployment of PSCs [18]. For the latter, considering only a few hundred nanometer thick HOIP thin films are assembled in the PSCs, the amount of $\mathrm{Pb}$ that could be released is very small $\left(\sim 0.4 \mathrm{~g} \mathrm{~Pb}\right.$ in a $1 \mathrm{~m}^{2}$ panel), and the amount of soluble $\mathrm{Pb}$ that could possibly be released into the environment is even smaller [19]. Moreover, such $\mathrm{Pb}$ release can be possibly mitigated by proper encapsulation and recycling strategies [20]. However, the $\mathrm{Pb}$ release during the fabrication of PSCs is rarely addressed. While numerous HOIP thin-film deposition techniques have been developed for fabricating high-PCE PSCs [2,3,9,21-27], the environmental impact of these techniques has not been evaluated. In particular, in the most commonly-used spin-coating based solution methods, only a very small portion of the $\mathrm{Pb}$-containing precursor materials are deposited into the final HOIP thin films, while the remainder is spun off

\footnotetext{
${ }^{1}$ State Key Laboratory for Artificial Microstructure and Mesoscopic Physics, Department of Physics, Peking University, Beijing 100871, China

${ }^{2}$ School of Engineering, Brown University, Providence, RI 02912, USA

${ }^{3}$ Materials Sciences Division, Lawrence Berkeley National Laborato, Berkeley, CA 94720, USA

${ }^{4}$ Chemical and Material Science Center, National Renewable Energy Laborator, Golden, CO 80401, USA

${ }^{5}$ Collaborative Innovation Center of Extreme Optics, Shanxi University, Taiyuan 030006, China

${ }^{6}$ State Key Laboratory for Mesoscopic Physics, Collaborative Innovation Center of Quantum Matter, School of Physics, Peking University, Beijing 100871, China

These authors contributed equally to this work.

*Corresponding author (email: iamzhurui@pku.edu.cn)
} 
$[3,7,8,21,22]$. A simple calculation (see Supplementary information) reveals that, the amount of $\mathrm{Pb}$ in the resultant HOIP film is typically less than $2 \%$ of that in the precursor solution $[8,26]$. Thus, $\sim 98 \%$ of $\mathrm{Pb}$ is wasted during the spin-coating process, which is difficult to dispose off or recycle. This is a serious pollution as well as a health risk to the future industrial workers. Besides, the waste of raw materials significantly adds to the fabrication cost of PSCs. Similar Pb-release issue also exists in other HOIP fabrication methods, such as blade coating and chemical vapor deposition. In this context, a Pb-release free, high-yield method for high-quality HOIP films is highly demanded.

Here, a fast-growing procedure (FGP) is introduced to address this issue. In the FGP, the concentration of the perovskite precursor solution is $0.01 \mathrm{molL}^{-1}$, which is $\sim 1 / 100$ of that in other conventional solution methods. The hot perovskite precursor solution is drop-cast onto a hot $\left(\sim 240^{\circ} \mathrm{C}\right)$ substrate, where a compact perovskite thin film grows in seconds accompanied by the rapid evaporation of the host solvent. No spin-coating or post-annealing treatment is needed. In contrast to other conventional solution methods, the utilization of precursor materials in this process is ultrahigh. Almost all the $\mathrm{Pb}$ in the deposited precursor solution presents in the final perovskite film in the FGP, reducing the cost and potential $\mathrm{Pb}$ pollution in the PSC fabrication [27]. However, we found that, using the conventional stoichiometric $\mathrm{PbI}_{2} \cdot \mathrm{CH}_{3} \mathrm{NH}_{3} \mathrm{I}$ (MAI) precursor solution (in dimethylformamide (DMF)), the FGP-processed PSCs showed poor current density $(J)$-voltage $(V)$ performance, severe hysteresis and limited reproducibility. This may be attributed to two reasons: i) The crystallization of $\mathrm{MAPbI}_{3}$ at high temperature $\left(240^{\circ} \mathrm{C}\right)$ does not lead to desirable microstructures for PSC operation [28]; ii) pure MA-based HOIPs can easily decompose at $240^{\circ} \mathrm{C}$, which makes the processing window for the phase-pure HOIP films very narrow [21]. Hence, the composition of perovskite precursor solution needs to be tailored for the success of the FGP. In this study, we replaced MAI with a mixture of $\mathrm{MACl}$ and $\mathrm{CH}\left(\mathrm{NH}_{2}\right)_{2} \mathrm{I}$ (FAI) with the same molarity in the precursor solution, forming the precursor composition of $\mathrm{PbI}_{2} \cdot(1-x) \mathrm{FAI} \cdot x \mathrm{MACl}$, $0 \leq x \leq 1$. While $\mathrm{MACl}$ can modulate the film crystallization dynamics, FAI can enhance the thermal stability and extend the absorption range of the as-deposited HOIP films $[6,29]$. By tuning the value of $x$, high-quality HOIP thin films with desirable microstructures and optoelectronic properties can be reproducibly fabricated through the simple and high-yield FGP.

\section{EXPERIMENTAL SECTION}

\section{Materials and substrate preparation}

MAI was synthesized from $\mathrm{CH}_{3} \mathrm{NH}_{2}$ and $\mathrm{HI}$ using the procedure reported in the literature [10]. FAI was synthesized from $\mathrm{CH}\left(\mathrm{NH}_{2}\right)_{2} \mathrm{COOH}$ and $\mathrm{HI}$ according to the reported literature [29]. Lead iodied $\left(\mathrm{PbI}_{2}\right)$ was purchased from Sigma Aldrich (China). 2,2',7,7'tetrakis[ $N, N$-di(4-methoxyphenyl)amino]-9,9'-spirobifluorene (Spiro-OMeTAD) was purchased from SunaTech (China). All liquid reagents, DMF and chlorobenzene (CB), were purchased from commercial sources (Acros, China) and used as received. Pre-patterned fluorine doped tin oxide (FTO) glasses ( $7 \Omega / \mathrm{sq}$ ) were purchased from OPV-Tech (China).

\section{Solar cell fabrication}

The pre-patterned FTO-coated glass substrates were sequentially cleaned with diluted detergent, deionized water, acetone, and isopropanol (IPA), and treated in a UV-ozone cleaner for $7 \mathrm{~min}$. The $\mathrm{TiO}_{2}$ layer was deposited by spin coating the $\mathrm{TiO}_{x}$ precursor solution at $3000 \mathrm{rpm}$ for $60 \mathrm{~s}$ followed by heating at $500^{\circ} \mathrm{C}$ for $30 \mathrm{~min}$ [30]. Then the $\mathrm{TiO}_{2}$ film and perovskite precursor solution were placed at the center and corner of a $240^{\circ} \mathrm{C}$ hot plate, respectively. About $60 \mu \mathrm{L}$ of the hot perovskite precursor solution was dropped onto the hot $\mathrm{TiO}_{2}$ film. Driven by the high temperature, the solvent would evaporate in 3-4s, and thus a dark film formed immediately. As soon as the film turned dark, it was transferred from the hotplate onto a cold metal board to cool down. The $p$-type spiro-OMeTAD $(80 \mathrm{mg}), 17.5 \mu \mathrm{L}$ of lithium bis(trifluoromethanesulfonyl)imide (Li-TFSI) solution $(520 \mathrm{mg}$ of Li-TFSI in $1 \mathrm{~mL}$ of acetonitrile) and $28.5 \mu \mathrm{L}$ of 4-tert-butylpyridine all dissolved in $1 \mathrm{~mL}$ of $\mathrm{CB}$ ) was then coated on perovskite active layer as the hole transporting layer. Finally, $80 \mathrm{~nm}$ of gold (Au) was evaporated onto the device through a shadow mask. Active area of the cell is $0.09 \mathrm{~cm}^{2}$.

\section{Characterizations}

The solar cells were illuminated under $100 \mathrm{~mW} \mathrm{~cm} \mathrm{~cm}^{-2}$ by a $150 \mathrm{~W}$ Class AAA solar simulator (XES-40S1, SAN-EI) with an AM 1.5G filter. Light intensity of $100 \mathrm{~mW} \mathrm{~cm}^{-2}$ was determined by a standard monocrystal silicon ( $\mathrm{Si}$ ) photodiode calibrated by the Newport TAC-PV lab. The $J-V$ curves were measured using a Keithley 2400 source-measure unit. The devices were measured under ambient conditions without encapsulation (temperature $\sim 20^{\circ} \mathrm{C}$, humidity $\sim 30 \%)$. 
Scanning electron microscopy (SEM) images were collected by an FEI Nova NanoSEM 430 field-emission SEM. The film thicknesses were measured by stylus profilometry (Bruker Dektak XT). The 2D X-ray diffraction (XRD) patterns were obtained using an X-ray diffractometer (D8 Advance, Bruker, Germany) with 2D detector (Vantec 500) using $\mathrm{Cu} \mathrm{Ka}$ radiation, with $0.02^{\circ}$ step and 2 s/step dwell. Conducting atomic force microscope (c-AFM) images (MFP-3D Origin, Oxford Instruments, UK) were collected using an electrically-conductive diamond-coated tip in contact mode. Current maps of the perovskite films were captured, using 256 scan lines and 256 scan points, with a scan rate of $0.5 \mathrm{~Hz}$ for each image. The film thickness was measured by stylus profilometry (Bruker Dektak XT).

\section{RESULTS AND DISCUSSION}

\section{Morphology}

Fig. 1a schematically shows the FGP method. First, the dilute HOIP precursor solution in DMF with a composition of $\mathrm{PbI}_{2} \cdot(1-x)$ FAI $x \mathrm{MACl}$ and the dense $\mathrm{TiO}_{2}$-coated FTO substrates were kept on the same hot plate at $240^{\circ} \mathrm{C}$. Then, $\sim 60 \mu \mathrm{L}$ of the hot precursor solution was drop-cast onto the hot substrate. Due to the high temperature, the solvent evaporated rapidly, leaving a dark film on the substrate in $4 \mathrm{~s}$. The hot substrate was then immediately removed from the hot plate and quenched on a cold metal plate, allowing the cooling of the HOIP film. Fig. 1b shows the optical microscopy (OM) images of the FGP-deposited HOIP films from $\mathrm{PbI}_{2} \cdot(1-x) \mathrm{FAI} \cdot x \mathrm{MACl}$ precursors for $x=0$, $0.25,0.5$ and 1 , respectively. In the case of $x=0$, full-coverage HOIP films cannot be obtained. With the increase of $x$, the coverage of the HOIP film improves significantly. When $x=0.5$, full-coverage HOIP films with large (millimeter-scale) grain clusters can be observed under the OM. With further increase in $x$, the morphologies of the HOIP films appear similar under the OM.

To reveal the detailed microstructures of these HOIP films from $\mathrm{PbI}_{2} \cdot(1-x) \mathrm{FAI} \cdot x \mathrm{MACl}$ precursors with $0.5 \leq \mathrm{x} \leq 1$, SEM images were tested and shown in Fig. $2 a-d$. It is clear that the grain clusters observed in the OM are not single-crystals but rather composed of sub-micrometer grains. For $x=0.5$, pinhole defects that are not visible in the $\mathrm{OM}$ can be seen in the SEM image in Fig. 2a. However, when $x$ is increased to 0.75 or beyond, no obvious pinholes are observed. SEM images of this film under a series of resolutions were tested and shown in Fig. S1 in the Supplementary information, revealing the full coverage of the
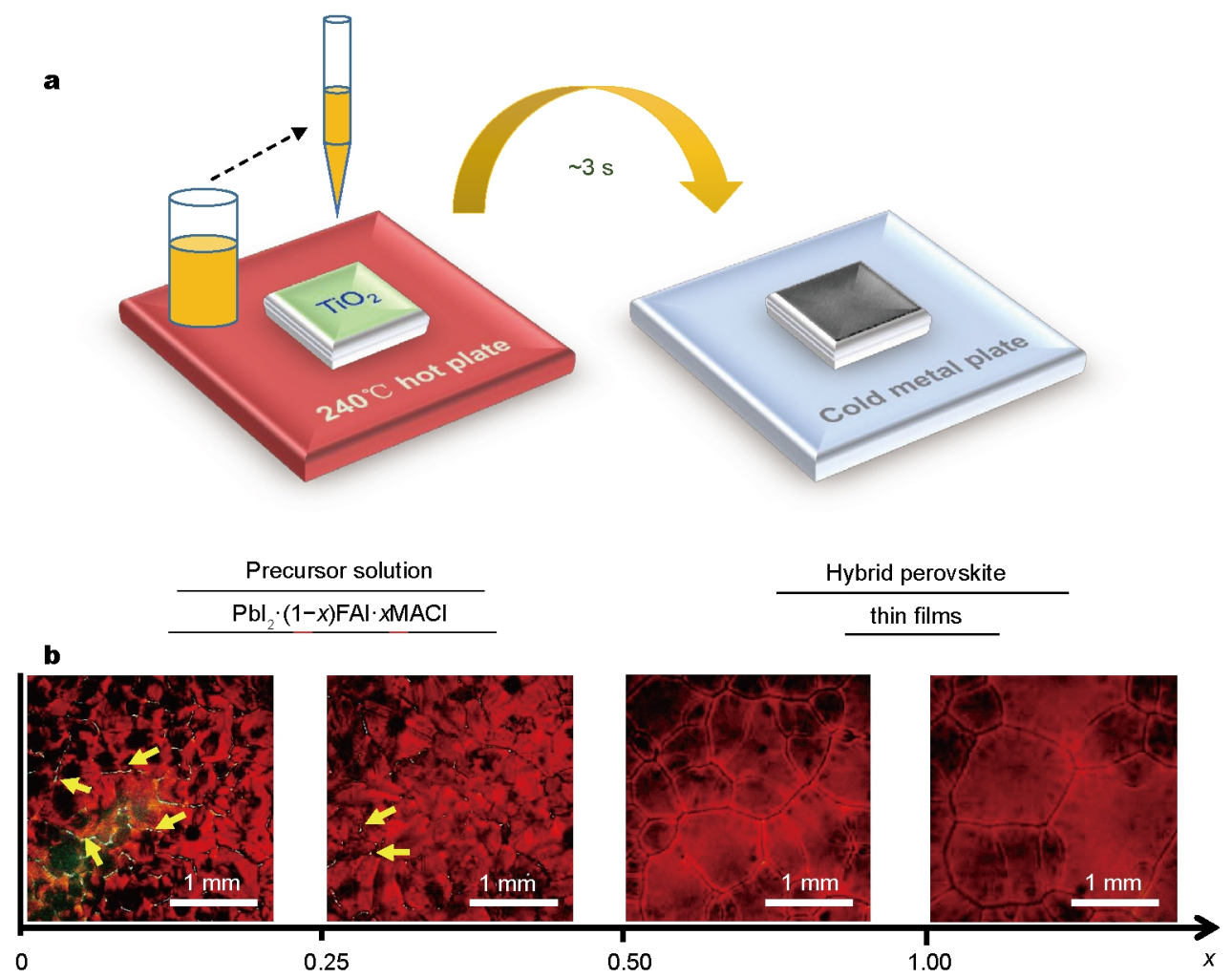

Figure 1 (a) Schematic of the fast-growing procedure. (b) Optical microscopy images of perovskite films from different precursor solutions. 

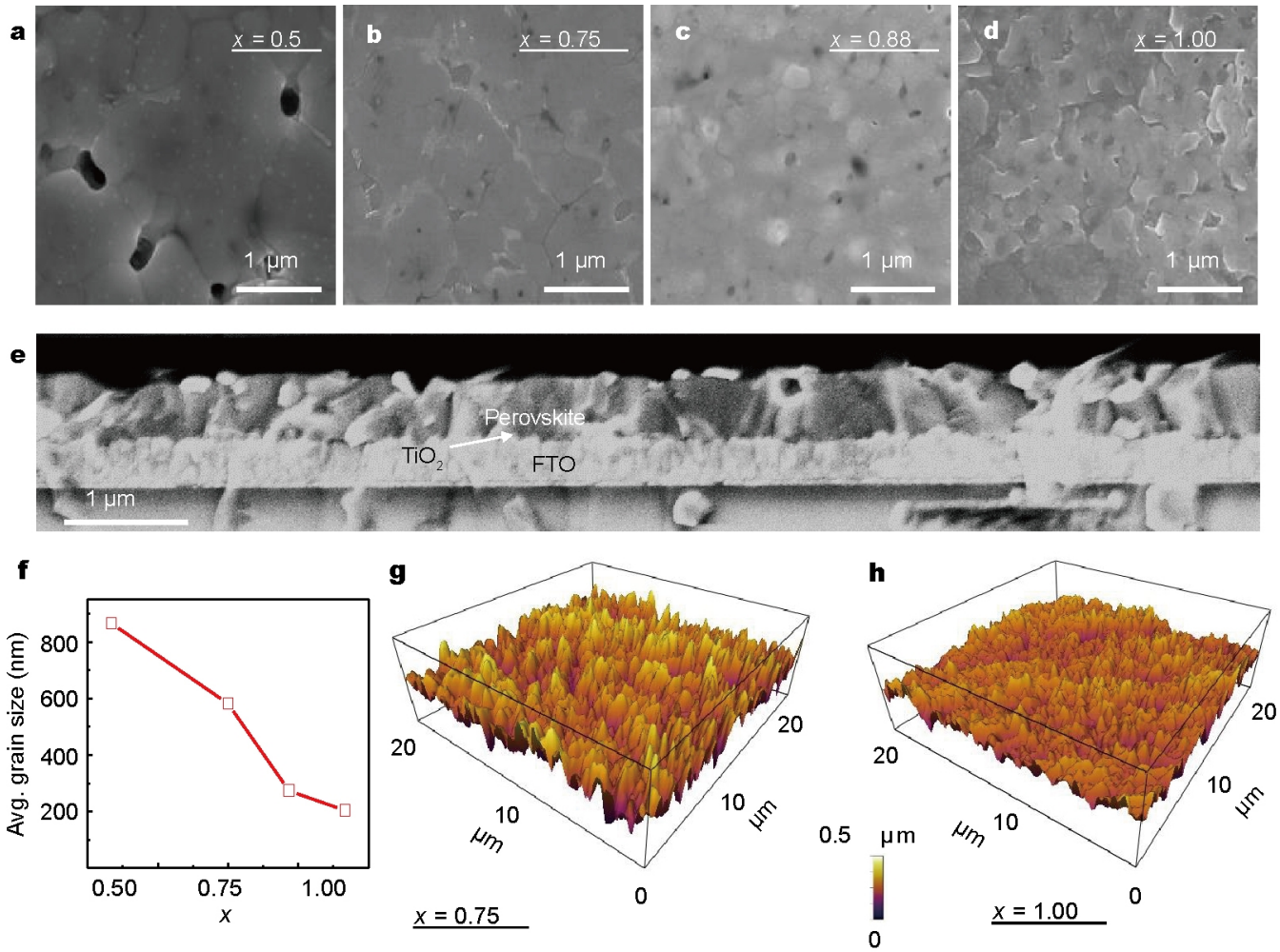

Figure 2 (a-d) Top view SEM images of the perovskite films derived from the precursor composition of $\mathrm{PbI}_{2} \cdot(1-x) \mathrm{FAI} \cdot x \mathrm{MACl}$ with different $x$ values; (e) the cross-sectional SEM image of the perovskite film derived from $\mathrm{PbI}_{2} \cdot(1-x) \mathrm{FAI} \cdot x \mathrm{MACl}(x=0.75)$; (f) the relationship between the average grain sizes and $x$ values; $(\mathrm{g}, \mathrm{h})$ AFM images of perovskite films derived from $\mathrm{PbI}_{2} \cdot(1-x) \mathrm{FAI} \cdot x \mathrm{MACl}(x=0.75)$ and $\mathrm{PbI} \cdot \mathrm{MACl}$.

HOIP film on the $\mathrm{TiO}_{2}$ substrate. The uniformity and compactness of this HOIP film were further confirmed by the cross-sectional SEM image in Fig. 2e. The origin and elimination of the pinholes in the HOIP films are closely related to the grain size. The average grain size of the HOIP films with $x=0.50,0.75,0.88$ and 1.00 were measured with image analysis approach and the results are shown in Fig. $2 \mathrm{f}[31-33]$. As seen in Fig. 2f, with the increase of $x$ (MACl content in the precursor solution), the grain size decreases gradually. This is consistent with the fact that $\mathrm{MACl}$ modifies the crystallization kinetics of HOIPs, as previously studied in literatures [34,35]. In the FGP, the presence of $\mathrm{MACl}$ affects the nucleation and crystallization, leading to a better morphology in HOIP thin films. Fig. $2 \mathrm{~g}, \mathrm{~h}$ show the 3D AFM images of the thin films derived from precursor solutions of $\mathrm{PbI}_{2} \cdot(1-x) \mathrm{FAI} \cdot x \mathrm{MACl}$ with $x=0.75$ and 1.00 , respectively. The apparent grain sizes of the films are similar to those observed in SEM images. The root-mean-square (RMS) roughness for $x=0.75(26 \mathrm{~nm})$ is slightly higher than that for $x=1.00(20 \mathrm{~nm})$, which should be expected given that deeper grooves usually form between larger crystal grains [28]. These above results confirm the significance of the composition, especially the
$\mathrm{MACl}$ fraction, in the fabrication of desirable thin-film microstructures in the FGP. In addition to composition, the morphologies of the FGP-deposited HOIP thin films are also dependent on the concentration of precursor solutions. As seen in Fig. 2e, in the most typical deposition process (using $0.01 \mathrm{molL}^{-1} \mathrm{PbI}_{2} \cdot(1-x) \mathrm{FAI} \cdot x \mathrm{MACl}, x=0.75$, DMF solution), a HOIP thin film with a uniform thickness of about $600 \mathrm{~nm}$ forms on the substrate.

In the FGP, a precursor-solution volume of $60 \mu \mathrm{L}$ is found to be necessary to fully cover the substrate with an area of $1.5 \mathrm{~cm} \times 1.5 \mathrm{~cm}$. Since almost all the precursors are deposited into the HOIP film, the overall thickness of the HOIP film is determined by the precursor-solution concentration, as tested by the stylus profilometry and illustrated in Table S1 (in Supplementary information). Extremely dilute $\left(\leq 0.01 \mathrm{molL}^{-1}\right)$ precursor solutions may lead to incomplete coverage of perovskites on the substrate, which is typical for Volmer-Weber crystallization of perovskite thin films from the solution [28].

\section{Thermal stability}

Fig. 3a, b shows the ex-situ 2D XRD patterns of the films derived from precursor solutions of $\mathrm{PbI}_{2} \cdot(1-x) \mathrm{FAI} \cdot x \mathrm{MACl}$ 

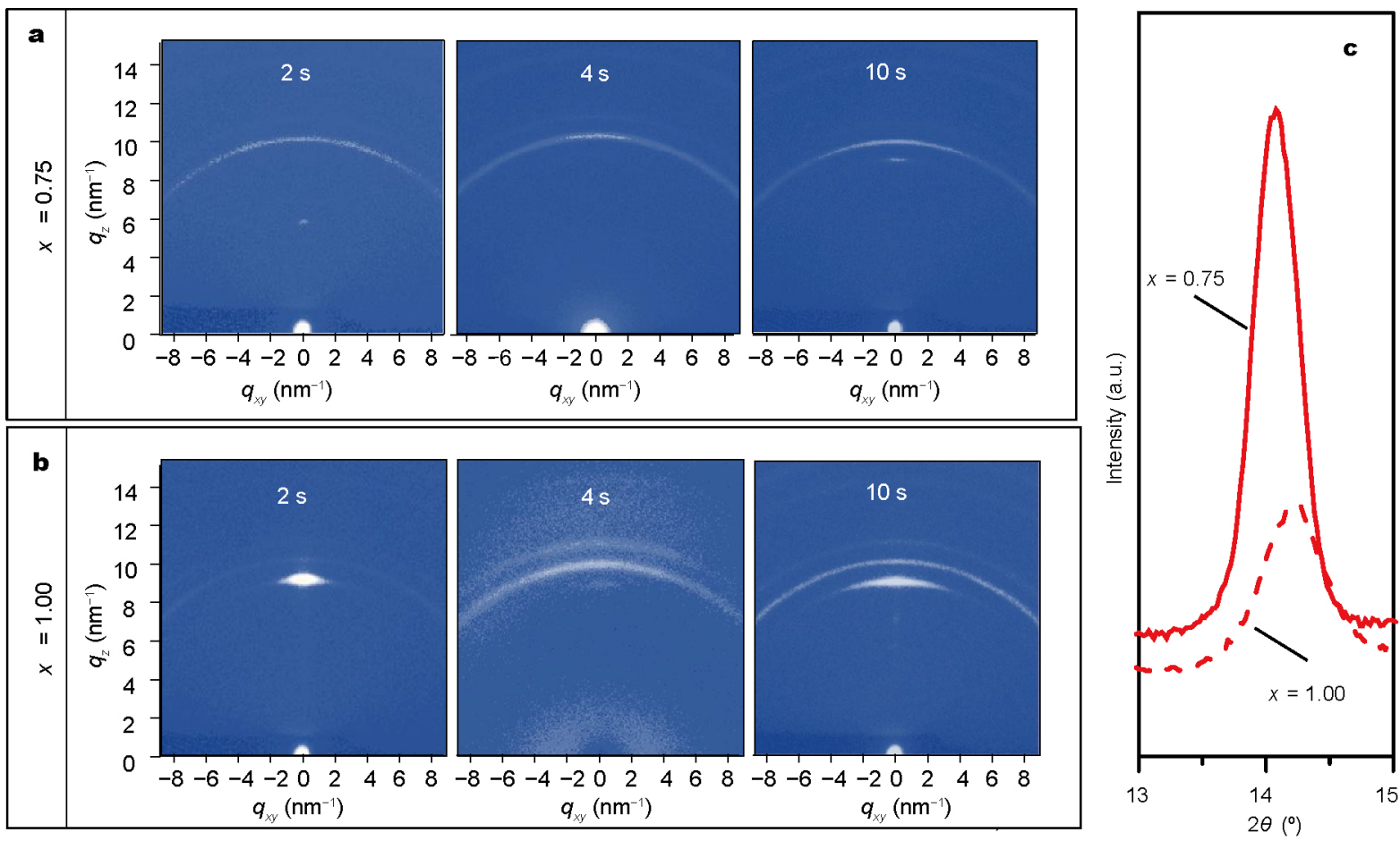

Figure 3 (a) $2 \mathrm{D}$ XRD spectra of the FGP-deposited HOIP film derived from $\mathrm{PbI}_{2} \cdot(1-x) \mathrm{FAI} \cdot x \mathrm{MACl}, x=0.75$ with different heating durations, the arrow points to the (110) reflection peak; (b) 2D XRD spectra of the FGP-deposited HOIP film derived from $\mathrm{PbI}_{2} \cdot(1-x) \mathrm{FAI} \cdot x \mathrm{MACl}, x=1.00$ with different heating durations; (c) XRD patterns of the FGP-deposited HOIP films with a heating duration of $4 \mathrm{~s}$.

with $x=0.75$ and 1.00 , respectively. The films were prepared with the FGP and taken away from the hot plate at different $t$. $t$ is defined as the heating duration before the films are quenched. 2D XRD characterization aims at evaluating the stability of the FGP-deposited HOIP films. As seen in Fig. $3 \mathrm{a}$, for both $x=0.75$ and 1.00 , the XRD patterns suggest that crystallization of HOIPs completes at $t=4 \mathrm{~s}$ during the FGP. Prolonged $t(10 \mathrm{~s})$ results in significant decomposition of HOIP films for $x=1.00$, whereas only negligible $\mathrm{PbI}_{2}$ formation is observed for $x=0.75$. The integrated XRD patterns from Fig. 3a, b $(t=4 \mathrm{~s})$ show a shift of the HOIP characteristic peak from $2 \theta=14.2^{\circ}$ to $14.0^{\circ}$, confirming the incorporation of $\mathrm{FA}^{+}$cation in the HOIP crystal. And the $\mathrm{FA}^{+}$-containing HOIP film shows significantly enhanced thermal stability. It survives longer at $240^{\circ} \mathrm{C}$ in the FGP.

\section{Photovoltaic performance}

The PSC performances were further studied for the FGPdeposited HOIP thin films based on the precursor composition of $\mathrm{PbI}_{2} \cdot(1-x) \mathrm{FAI} \cdot x \mathrm{MACl}$ with different $x$ values. The average values of the photovoltaic parameters are listed in Table 1. Distributions of the photovoltaic parameters are shown in Fig. 4. The PSCs employ a regular structure with HOIP thin films sandwiched between FTO/compact- $\mathrm{TiO}_{2}$ anodes and spiro-OMeTAD/Au cathodes. When $x<0.5$, no photovoltaic effect in PSCs is observed. This is consistent with OM results in Fig. 1b. Many micro-scale pinholes exist in the HOIP thin films, which lead to unexpected contacts between the spiro-OMeTAD and $\mathrm{TiO}_{2}$. For $x=0.5$, a modest device performance is observed, which is attributed to the presence of nanoscale pinholes in HOIP thin films. When $x=0.75$, the PSC achieved the highest average PCE of $14.6 \%$ with an open circuit voltage $\left(V_{\text {oc }}\right)$ of $0.97 \mathrm{~V}$, a short circuit current density $\left(J_{\mathrm{sc}}\right)$ of $22.8 \mathrm{~mA} \mathrm{~cm}^{-2}$ and a fill factor $(\mathrm{FF})$ of 0.66 . With the increase of $x$, the surface of the HOIP film is more and more compact, while the grain size is smaller and smaller. In general, large grains are favorable for charge transporting in the HOIP films due to the low grain boundary density [36]. Therefore, when the surface of the HOIP film is compact enough, further increase

Table 1 Average values of the photovoltaic parameters of perovskite solar cells derived from various precursor compositions

\begin{tabular}{ccccc}
\hline $\mathrm{PbI}_{2}+(\mathrm{FAI})_{1-x}(\mathrm{MACl})_{x}$ & $V_{\mathrm{oc}}(\mathrm{V})$ & $J_{\mathrm{sc}}\left(\mathrm{mA} \mathrm{cm}^{-2}\right)$ & $\mathrm{FF}$ & $\mathrm{PCE}(\%)$ \\
\hline$x=0$ & 0 & 0 & 0 & 0 \\
$x=0.5$ & 0.99 & 17.5 & 0.47 & 8.13 \\
$x=0.75$ & 0.97 & 22.8 & 0.66 & 14.60 \\
$x=0.88$ & 0.98 & 18.9 & 0.54 & 10.37 \\
$x=1.00$ & 0.97 & 18.3 & 0.49 & 8.70 \\
\hline
\end{tabular}



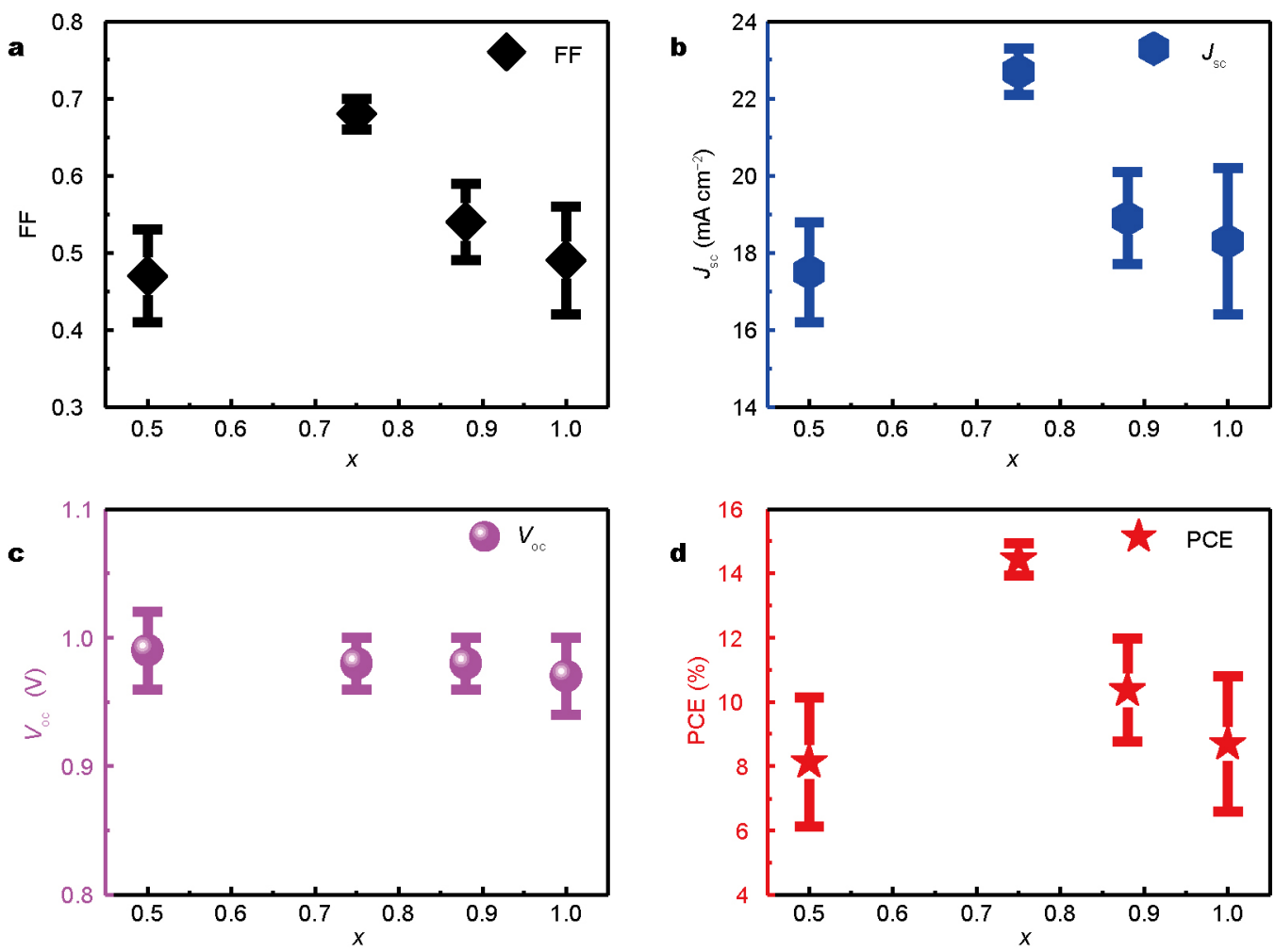

Figure 4 Distribution of the photovoltaic parameters of perovskite solar cells based on $\mathrm{PbI}_{2} \cdot(1-x) \mathrm{FAI} \cdot x \mathrm{MACl}$ with different $x$ values.

of $x$ only leads to small grains, which lower the overall photovoltaic performance. From Fig. 4, it is found that the reproducibility of photovoltaic performance is also the best when using a precursor composition of $\mathrm{PbI}_{2} \cdot(1-x) \mathrm{FAI} \cdot x \mathrm{MACl}, x=0.75$. Wider variations in photovoltaic parameters are observed when $x>0.75$ or $x<0.75$. The former can be attributed to the poor thermal stability in $\mathrm{FA}^{+}$-less HOIPs as shown in Fig. 3a, b, while the latter can be explained by the incomplete HOIP film coverage as shown in Fig. 2a.

The champion device derived from $\mathrm{PbI}_{2} \cdot(1-x) \mathrm{FAI} \cdot x \mathrm{MA}-$
Cl with $x=0.75$ shows a PCE of $15.2 \%$ with an $V_{\text {oc }}$ of $0.98 \mathrm{~V}$, a $J_{\text {sc }}$ of $22.8 \mathrm{~mA} \mathrm{~cm}^{-2}$ and an FF of 0.68 (Fig. 5a). The steady-state output of this PSC at the maximum power point $(V=0.78 \mathrm{~V})$ is shown in Fig. $5 \mathrm{~b}$. The photocurrent density $(J)$ stabilizes at $17.8 \mathrm{~mA} \mathrm{~cm}^{-2}$, yielding a stabilized PCE of $13.9 \%$. Incident photon-to-current conversion efficiency (IPCE) spectrum was recorded for this PSC (Fig. S2 in Supplementary information), showing an integrated $J_{\mathrm{sc}}$ of $21.6 \mathrm{~mA} \mathrm{~cm}^{-2}$, approaching the value extracted from the $J-V$ curve.

It is also interesting that the PSCs fabricated using the
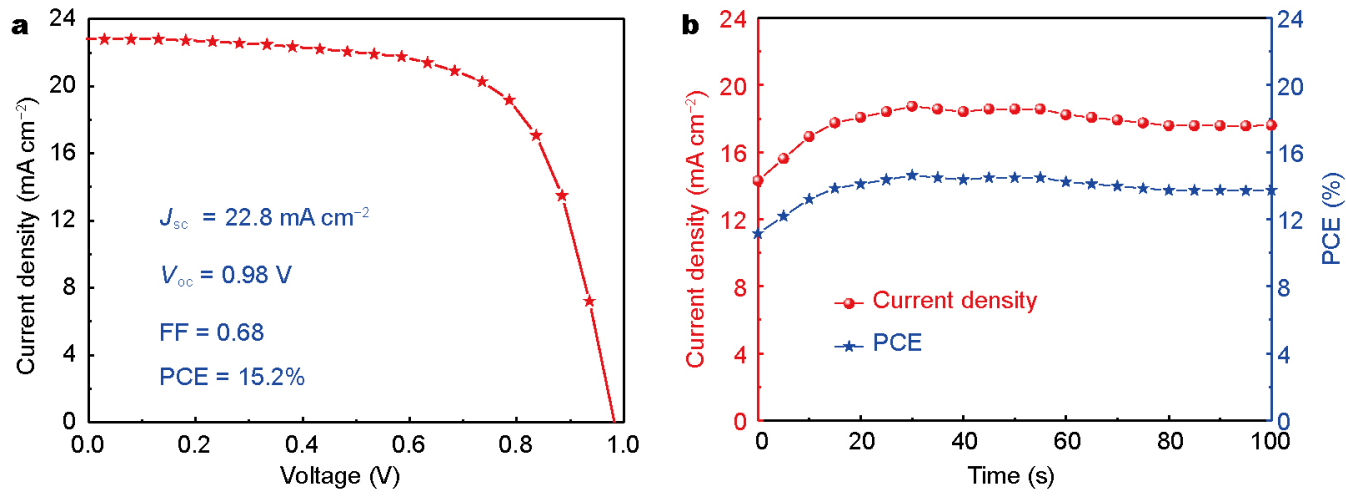

Figure 5 (a) $J-V$ curve of the champion device; (b) stabilized output of the photocurrent density and PCE at the maximum power point $(V=0.78 \mathrm{~V})$. 

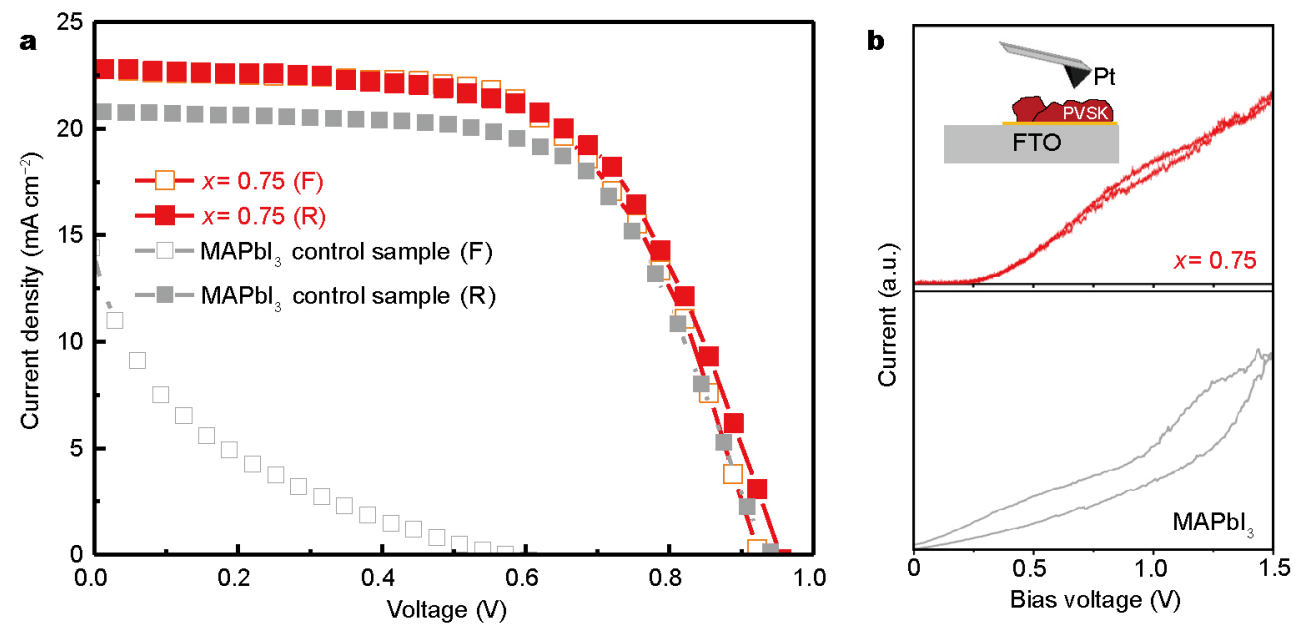

Figure 6 (a) $J$ - $V$ curves under different scan directions of perovskite solar cells based on $\mathrm{PbI}_{2} \cdot(1-x) \mathrm{FAI} \cdot x \mathrm{MACl}, x=0.75$ amd $\mathrm{MAPbI}_{3}$; (b) $J-V$ curves under different scan directions performed on a single perovskite grain for both samples with c-AFM.

FGP with the optimized composition of $\mathrm{PbI}_{2} \cdot(1-x) \mathrm{FAI}$. $x \mathrm{MACl}, x=0.75$, show suppressed hysteresis in the $J-V$ response, as shown in Fig. 6a. For comparison, a control PSC based on the regular $\mathrm{MAPbI}_{3}$ composition was also examined. The FGP-deposited $\mathrm{MAPbI}_{3}$ film exhibits a similar desirable morphology (Fig. S3 in Supplementary information). However, significant $J$ - $V$ hysteresis is observed for the relevant PSC. To gain more understanding about the origin of these differences, $J-V$ scans in forward and reserve directions (in dark) were performed on a single grain of the HOIP films using c-AFM, as shown in Fig. $6 \mathrm{~b}$. The $J-V$ hysteresis in Fig. $6 \mathrm{~b}$ from the c-AFM measurements is consistent with that in Fig. 6a from the PSC measurement. This indicates that the origin of the hysteresis could be primarily from the intrinsic electronic properties of the HOIP grains. Therefore, tailoring the composition of the HOIP grains by tuning the precursor composition is key to suppressing the hysteresis in PSCs fabricated with the FGP.

\section{CONCLUSION}

In closing, the FGP enables the deposition of high-quality HOIP thin films with precursor solutions at very low concentrations $\left(\sim 0.01 \mathrm{~mol} \mathrm{~L}^{-1}\right)$. All the $\mathrm{Pb}$-containing materials are deposited into the final perovskite films. The $\mathrm{Pb}$ release in the fabrication of PSCs can be avoided. Characteristics (compactness, grain size, thermal stability, etc.) of the HOIP thin films are significantly determined by the precursor composition. Based on the optimized precursor composition of $\mathrm{PbI}_{2} \cdot(1-x) \mathrm{FAI} \cdot x \mathrm{MACl}, x=0.75$, the best-quality FGP-deposited films are obtained. PSCs made with the optimized precursor composition deliver PCEs exceeding
$15 \%$ with suppressed hysteresis and high reproducibility. The success of the FGP represents a new direction for studies towards high-yield, low-cost fabrication of PSCs.

Received 28 March 2017; accepted 2 May 2017; published online 2 June 2017

1 Kojima A, Teshima K, Shirai Y, et al. Organometal halide perovskites as visible-light sensitizers for photovoltaic cells. J Am Chem Soc, 2009, 131: 6050-6051

2 Burschka J, Pellet N, Moon SJ, et al. Sequential deposition as a route to high-performance perovskite-sensitized solar cells. Nature, 2013, 499: 316-319

3 Liu M, Johnston MB, Snaith HJ. Efficient planar heterojunction perovskite solar cells by vapour deposition. Nature, 2013, 501: 395-398

4 Im JH, Jang IH, Pellet N, et al. Growth of $\mathrm{CH}_{3} \mathrm{NH}_{3} \mathrm{PbI}_{3}$ cuboids with controlled size for high-efficiency perovskite solar cells. Nat Nanotech, 2014, 9: 927-932

5 Zhou H, Chen Q, Li G, et al. Interface engineering of highly efficient perovskite solar cells. Science, 2014, 345: 542-546

6 Jeon NJ, Noh JH, Yang WS, et al. Compositional engineering of perovskite materials for high-performance solar cells. Nature, 2015, 517: 476-480

7 Zhou Y, Yang M, Wu W, et al. Room-temperature crystallization of hybrid-perovskite thin films via solvent-solvent extraction for high-performance solar cells. J Mater Chem A, 2015, 3: 8178-8184

8 Liu T, $\mathrm{Hu} \mathrm{Q}, \mathrm{Wu}$ J, et al. Mesoporous $\mathrm{PbI}_{2}$ scaffold for high-performance planar heterojunction perovskite solar cells. Adv Energ Mater, 2016, 6: 1501890

9 Zhao L, Luo D, Wu J, et al. Perovskite solar cells: high-performance inverted planar heterojunction perovskite solar cells based on lead acetate precursor with efficiency exceeding 18\% (Adv. Funct. Mater. 20/2016). Adv Funct Mater, 2016, 26: 3551-3551

$10 \mathrm{Hu} \mathrm{Q}, \mathrm{Wu}$ J, Jiang C, et al. Engineering of electron-selective contact for perovskite solar cells with efficiency exceeding $15 \%$. ACS Nano, 2014, 8: 10161-10167

11 Wei J, Shi C, Zhao Y, et al. Potentials and challenges towards application of perovskite solar cells. Sci China Mater, 2016, 59: 769-778 
12 Niu G, Li W, Li J, et al. Progress of interface engineering in perovskite solar cells. Sci China Mater, 2016, 59: 728-742

13 Yang WS, Noh JH, Jeon NJ, et al. High-performance photovoltaic perovskite layers fabricated through intramolecular exchange. Science, 2015, 348: 1234-1237

14 Li X, Bi D, Yi C, et al. A vacuum flash-assisted solution process for high-efficiency large-area perovskite solar cells. Science, 2016, 353 : $58-62$

15 Stranks SD, Eperon GE, Grancini G, et al. Electron-hole diffusion lengths exceeding 1 micrometer in an organometal trihalide perovskite absorber. Science, 2013, 342: 341-344

16 Xing G, Mathews N, Sun S, et al. Long-range balanced electronand hole-transport lengths in organic-inorganic $\mathrm{CH}_{3} \mathrm{NH}_{3} \mathrm{PbI}_{3}$. Science, 2013, 342: 344-347

17 Noh JH, Im SH, Heo JH, et al. Chemical management for colorful, efficient, and stable inorganic-organic hybrid nanostructured solar cells. Nano Lett, 2013, 13: 1764-1769

18 Babayigit A, Ethirajan A, Muller M, et al. Toxicity of organometal halide perovskite solar cells. Nat Mater, 2016, 15: 247-251

19 Hailegnaw B, Kirmayer S, Edri E, et al. Rain on methylammonium lead iodide based perovskites: possible environmental effects of perovskite solar cells. J Phys Chem Lett, 2015, 6: 1543-1547

20 Zhou Y, Zhu K. Perovskite solar cells shine in the "Valley of the Sun". ACS Energ Lett, 2016, 1: 64-67

21 Yang $\mathrm{M}$, Zhou Y, Zeng Y, et al. Square-centimeter solution-processed planar $\mathrm{CH}_{3} \mathrm{NH}_{3} \mathrm{PbI}_{3}$ perovskite solar cells with efficiency exceeding 15\%. Adv Mater, 2015, 27: 6363-6370

22 Deng Y, Peng E, Shao Y, et al. Scalable fabrication of efficient organolead trihalide perovskite solar cells with doctor-bladed active layers. Energ Environ Sci, 2015, 8: 1544-1550

23 Jeon NJ, Noh JH, Kim YC, et al. Solvent engineering for highperformance inorganic-organic hybrid perovskite solar cells. Nat Mater, 2014, 13: 897-903

24 Mei A, Li X, Liu L, et al. A hole-conductor-free, fully printable mesoscopic perovskite solar cell with high stability. Science, 2014, 345: 295-298

25 Ye F, Chen H, Xie F, et al. Soft-cover deposition of scaling-up uniform perovskite thin films for high cost-performance solar cells. Energ Environ Sci, 2016, 9: 2295-2301

26 Liu D, Gangishetty MK, Kelly TL. Effect of $\mathrm{CH}_{3} \mathrm{NH}_{3} \mathrm{PbI}_{3}$ thickness on device efficiency in planar heterojunction perovskite solar cells. J Mater Chem A, 2014, 2: 19873-19881

27 Liu TH, Chen K, Hu Q, et al. Fast-growing procedure for perovskite films in planar heterojunction perovskite solar cells. Chin Chem Lett, 2015, 26: 1518-1521

28 Zhou Y, Game OS, Pang S, et al. Microstructures of organometal trihalide perovskites for solar cells: their evolution from solutions and characterization. J Phys Chem Lett, 2015, 6: 4827-4839

29 Pang $\mathrm{S}, \mathrm{Hu} \mathrm{H}$, Zhang J, et al. $\mathrm{NH}_{2} \mathrm{CH}=\mathrm{NH}_{2} \mathrm{PbI}_{3}$ : an alternative organolead iodide perovskite sensitizer for mesoscopic solar cells. Chem Mater, 2014, 26: 1485-1491
30 Docampo P, Ball JM, Darwich M, et al. Efficient organometal trihalide perovskite planar-heterojunction solar cells on flexible polymer substrates. Nat Commun, 2013, 4: 2761

31 Wang N, Zhou Y, Ju MG, et al. Heterojunction-depleted lead-free perovskite solar cells with coarse-grained B- $\gamma-\mathrm{CsSnI}_{3}$ thin films. Adv Energ Mater, 2016, 6: 1601130

32 Zhou Y, Vasiliev AL, Wu W, et al. Crystal morphologies of organolead trihalide in mesoscopic/planar perovskite solar cells. J Phys Chem Lett, 2015, 6: 2292-2297

33 Reid OG, Yang M, Kopidakis N, et al. Grain-size-limited mobility in methylammonium lead iodide perovskite thin films. ACS Energ Lett, 2016, 1: 561-565

34 Zhao Y, Zhu K. $\mathrm{CH}_{3} \mathrm{NH}_{3} \mathrm{Cl}$-assisted one-step solution growth of $\mathrm{CH}_{3} \mathrm{NH}_{3} \mathrm{PbI}_{3}$ : structure, charge-carrier dynamics, and photovoltaic properties of perovskite solar cells. J Phys Chem C, 2014, 118: 9412-9418

35 Zuo C, Ding L. An 80.11\% FF record achieved for perovskite solar cells by using the $\mathrm{NH}_{4} \mathrm{Cl}$ additive. Nanoscale, 2014, 6: 9935-9938

36 Xiao Z, Dong Q, Bi C, et al. Solvent annealing of perovskite-induced crystal growth for photovoltaic-device efficiency enhancement. Adv Mater, 2014, 26: 6503-6509

Acknowledgments This work was financially supported by the National Basic Research Program of China (973 Program) (2015CB932203), the National Natural Science Foundation of China (61377025, 91433203, and 11121091), and the Young 1000 Talents Global Recruitment Program of China. Liu F and Russell TP were supported by the US Office of Naval Research under contract N00014-15-1-2244. Zhou Y and Padture NP acknowledge the support from the US National Science Foundation (DMR-1305913 and OIA-1538893) for the work performed at Brown University. The authors thank Prof. Xinqiang Wang for the calibration of solar simulator.

Author contributions Zhu R, Liu T and Chen $\mathrm{K}$ developed the fast-growing procedure (FGP). Zhu R and Liu T optimized the precursor composition and established the relationship between the film properties and precursor solutions. Zhou Y tested the corss-section SEM images, 2D XRD, AFM, c-AFM and analyzed the underlying mechanism in this study. Hu Q helped with constructing the regular structure perovskite solar cells. Zhang Y synthesised the FAI used in this study. Yang W and Luo D helped to optimize the performance of PSCs. Wu J tested the top-view SEM images. Ye F calibrated the solar simulator. $\mathrm{Hu} \mathrm{Q}$, Liu $\mathrm{F}$ and Russell $\mathrm{T}$ helped to analyze the crystal structure for various perovskite films. Liu $\mathrm{T}$ and Zhou Y prepared the manuscript. Zhu K, Russell T, Padture N and Gong Q helped to revise the manuscript. The final version of the manuscript was approved by all authors.

Conflict of interest The authors declare they have no conflict of interest.

Supplementary information Supporting data are available in the online version of the paper. 


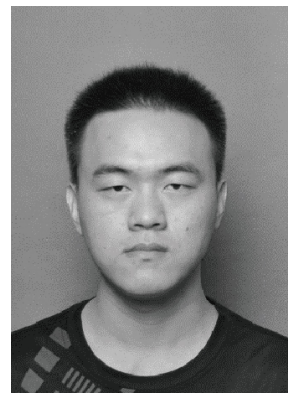

Tanghao Liu is a PhD candidate at the Department of Physics, Peking University. He received his Bachelor's degree from Huazhong University of Science and Technology in 2013. His research focuses on the perovskite solar cells.

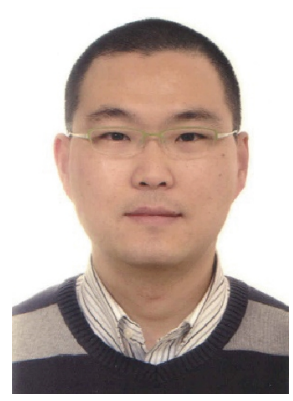

Rui Zhu is an associate professor in the State Key Laboratory of Artificial Microstructure and Mesoscopic Physics, Department of Physics, Peking University. He received his Bachelor's degree from Nanjing University in 2003 and PhD degree from Fudan University in 2007. He joined the Department of Physics at Peking University in 2013. His research focuses on the development of advanced photovoltaic materials and devices.

\section{优化快速成膜工艺中的前驱体组分以制备致密、稳定的钙针矿薄膜}

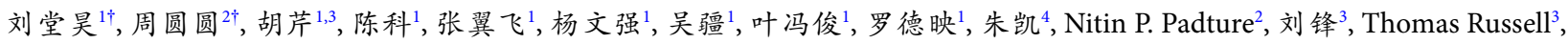
朱瑞 ${ }^{1,5,6^{*}}$, 龚旗煌 $1,5,6$

摘要 快速成膜工艺提供了一种简单、高产率、无铅释放的䥻钛矿薄膜制备方法. 在这一方法中, 低浓度的钲钛矿前驱体溶液被滴到 $240^{\circ} \mathrm{C}$ 的热衬底上, 伴随着溶剂在高温条件下的迅速挥发, 钙钛矿在衬底表面迅速结晶, 生长成一层薄膜. 在此过程中, 所有含铅的原材料都被沉 积到钻钛矿薄膜中, 含铅原材料的浪费和铅释放导致的污染都被显著降低. 这种方法制备的钻钛矿薄膜的性质可以由前驱体溶液的组分 调节. $\mathrm{CH}_{3} \mathrm{NH}_{3} \mathrm{Cl}(\mathrm{MACl})$ 可以调节结晶过程, 有助于提高薄膜表面覆盖率. $\mathrm{CH}\left(\mathrm{NH}_{2}\right)_{2} \mathrm{I}$ ( $\mathrm{FAI}$ ) 有助于提高钙钛矿薄膜的热稳定性. 当前驱体组 分为 $\mathrm{PbI}_{2} \cdot(1-x) \mathrm{FAI} \cdot x \mathrm{MACl}, x=0.75$ 时, 快速成膜工艺制备的钙钛矿膜达到最优化性质, 由此制备的平面结太阳电池可以实现超过 $15 \%$ 的能量 转换效率, 迟滞现象很小, 并且重复性良好. 